\title{
Exploration of SPOC+ Mixed Teaching Mode of Pharmacy Course Based on Innovative Applied Talents Training
}

\author{
Wanzhong Li', Bo Song ${ }^{\mathrm{a}}$, Yuanyuan Gao ${ }^{\mathrm{b}}$, Bo Zhang ${ }^{\mathrm{c}}$ and \\ Yanjie Li ${ }^{\mathbf{d}}$ \\ School of Pharmacy, Weifang Medical University, Weifang 261053, China \\ *Corresponding author e-mail: liwz@wfmc.edu.cn, ${ }^{a}$ songsbob@163.com, \\ byyg20062006@126.com, ${ }^{b}$ zhangbo@wfmc.edu.cn, ${ }^{d}$ liyj@wfmc.edu.cn
}

\begin{abstract}
Taking the pharmacy major pharmacy as the object, aiming at cultivating innovative applied talents, explore the connotation, characteristics, development of SPOC and its connection to hybrid teaching, from the perspectives of curriculum design, teaching theory, teaching resources, learning methods, learning and application, and comprehensive evaluation, we explore the SPOC+ mixed teaching model of pharmacy courses based on innovative applied talents, in order to provide reference and thinking for the reform of pharmaceutical education and teaching.
\end{abstract}

KEYWORDS: pharmacy, SPOC, mixed teaching

\section{Introduction}

Pharmacy is a comprehensive applied technology discipline that studies the basic theory of pharmaceutical preparations, prescription design, pharmaceutical excipients, preparation processes, quality standards and comprehensive applications. Pharmacy has strong craftsmanship and practicality. It is the main course for cultivating pharmacy professionals and plays an important role in innovative applied talents [1].

With the continuous advancement of science and technology, pharmaceutical equipment and pharmaceutical excipients, the development of pharmacy is changing with each passing day, and the requirements for the comprehensive ability of practitioners are getting higher and higher. Regular teaching methods are difficult to meet the needs of innovative application-oriented talent training. Based on this, explore the hybrid teaching mode of pharmacy course based on SPOC+, and provide reference for the combination of SPOC and classroom teaching in medical colleges. 


\section{Teaching status of pharmacy courses}

At present, the pharmacy course is mainly based on cramming, the students are relatively passive, and the overall learning effect is not good [2]; the classroom learning time is longer, mostly $40-50 \mathrm{~min}$, the students are prone to fatigue and lack attention. Concentration, it is difficult to digest and absorb the key points; due to the limitations of the course time, the teacher-student interaction and consolidation time accounted for less [3]; due to the long distance between the two classes, some students with poor learning initiative failed to review the review effectively. Those who are unable to attend classes due to illness may be obsessed with self-learning and lack flexibility and reversibility.

With the rapid advancement of science and technology in the world, especially in the fields of life, materials, electronics and information, the content of pharmacy has been promoted. In order to ensure the safety, effectiveness, stability and control of drugs, students should be trained to master new drug formulations and new technologies. At present, there is a lack of professional applicability in teaching, and the pace of knowledge update is relatively slow, which cannot meet the changing needs of the pharmaceutical industry. Although the pharmacy courses try different teaching methods, such as heuristic teaching [4], case teaching [5], Sandwich teaching [6], PBL teaching [7], flip classroom teaching [8], etc., however, the organic integration of the teaching content and the target audience has not been carried out, and the students' innovation and entrepreneurial potential have not been effectively tapped, and the ideal teaching quality has not been achieved.

\section{Pharmacy online teaching and SPOC model development}

The development of contemporary mobile Internet and the popularity of mobile network terminals have improved the real-time interactive ability of the Internet and pushed the modern society into the era of information fragmentation [9]. The integration of Internet technology and medicine has continuously promoted the advancement and transformation of pharmaceutical technology. For college students who have grown up in the mobile Internet, learning channels are no longer limited to textbooks and reference books, and online media content updates and spreads faster. Under the new situation of mobile Internet, traditional classroom teaching methods face new challenges. College teachers should follow the general trend of the times, make full use of the advantages of mobile Internet, and actively improve existing teaching methods and means.

With the development of mobile Internet platforms, especially technologies such as cloud computing, big data and mobile internet, many new teaching resources such as MOOC and SPOC have emerged in recent years. The SPOC (Small Private Online Course) teaching model derived from MOOC is a small-scale restrictive online course [10]. SPOC is a new mode of organic teaching and traditional teaching. Teachers use the SPOC teaching platform to guide students to interact and transform students into active learning subjects. Based on the premise of sharing the open curriculum resources provided by MOOC, SPOC strengthens the teaching design 
and effective guidance, and continuously improves the teaching efficiency and learning effect [11].

\section{Exploration of pharmacy SPOC + mixed teaching mode}

Based on the pharmacy major of our school, the student population is fixed. However, the student population from the central and western regions is weak, and the teaching requirements for pharmacy courses are different. According to the differentiation phenomenon of the lecture objects, this problem can be solved through the SPOC+ mixed teaching mode, which can fully utilize the advantages of SPOC, micro-course and flip classroom, and realize the integration of online teaching and offline teaching to meet the individual needs of each student. To give students a better learning experience.

\subsection{Course Design Ideas}

Pharmacy is a technical, applied and practical course [12]. It combines the combination of theory and practice in teaching, and aims to use it in combination with the needs of pharmaceutical enterprises and institutions. Through designing different learning activities and creating Different situations and reform teaching methods allow students to master the basic theories, new technologies and new dosage forms related to pharmacy in a limited time, and at the same time have certain innovation and problem solving skills. The course's hybrid teaching model design: (1) online micro-classroom. It consists of "micro-knowledge teaching + subject cutting-edge lectures + assessment (practice, discussion)", and each knowledge point video is between 8-12 min. (2) Offline physical classrooms. It consists of "classroom instruction (knowledge point expansion) + group cooperation learning (discussion, experiment, trainee, internship) + assessment (job, report, design, presentation, final exam).

\subsection{Teaching theory fusion}

The pharmacy course mainly advocates the cognitive learning theory based on the teaching method. First, students are allowed to recognize the concepts, characteristics and theories of different dosage forms, and then explain the process, evaluation and examples. SPOC Hybrid Teaching focuses on student learning, combining online teaching resources and classroom teaching methods, and mobilizing students' initiative and initiative through lectures, cases, flipping classes, PBL, experiments, trainees, internships, etc. The independent construction of new knowledge is completed in the combination of teaching and learning, learning and training, and learning and training.

For example, in the Surfactant section, through the comparative cognitive analysis of ionic and nonionic surfactants, using flash animation to demonstrate the dispersion of drugs in oil or water and emulsification operation micro-video,

\section{Published by Francis Academic Press, UK}


enhance students' intuitive visualization of surfactants. Feeling and knowledge internalization; using heuristic teaching to guide students to analyze the emulsification of $\mathrm{W} / \mathrm{O}, \mathrm{O} / \mathrm{W}, \mathrm{W} / \mathrm{O} / \mathrm{W}, \mathrm{O} / \mathrm{W} / \mathrm{O}$; to promote students' mastery by learning the structural characteristics of surfactants Mechanism, lead to the basic characteristics of the critical micelle concentration (CMC), hydrophilic-lipophilic balance (HLB), Krafft point, defect point; problem introduction: What is the principle of drug solubilization and dissolution? Finally, let the students summarize the pharmaceutical use and precautions of the surfactant after class.

\subsection{Teaching resource integration}

Teaching resources mainly include network, multimedia, teaching materials, reference books, forums and so on. The teacher first obtains the micro video from the SPOC platform and the multimedia library, and then appropriately processes it in conjunction with the teaching objectives. For example, when teaching the "injection" section, since the injection is a sterile and sterile preparation, the hygiene requirements are very high. First, introduce the "Drug Administration Law", "Chinese Pharmacopoeia", GMP standards and other related content, browse the national CFDA website and the pharmacy forum, and check the toxic incidents related to injections, such as bacteriophage A injection, Houttuynia injection, Acanthopanax injection, Xinfu injection and other phytotoxic events, reflecting the quality problems caused by improper operation of the injection in the prescription, process, storage and other links, help students establish the principle of "peopleoriented, safety first" to cultivate and strengthen students' awareness of the rule of law and quality. Secondly, by showing the injection of physical objects and packaging, such as vitamin $\mathrm{C}$ injection, Brucea javanica oil injection, hydroxycamptothecin injection, Shuanghuanglian injection, increase students' interest in learning, guide students to master the classification of injections, and deepen the understanding of the characteristics of injections. Again, by watching micro-videos in the preparation and quality inspection of injections, students' understanding of the preparation process and quality control of injections will be deepened. Combine targeted exercises and discussions, strengthen students' mastery of key knowledge points, and gradually improve students' ability to learn and collaborate independently.

\subsection{Learning mode mixing}

The pharmacy curriculum blended teaching methods mainly include: (1) online and offline learning, online learning mainly includes resource learning through the Internet, course network, WeChat, QQ, etc., offline learning mainly includes classroom learning, group collaboration. Learning, problem exploration and learning. (2) The combination of theory and practice, theoretical study mainly includes teaching, case teaching, problem teaching, flipping classroom teaching, and heuristic teaching. Practical learning mainly includes experimental operation, trainee practice, and experimental program design. (3) It is required to mix the operation with the 
individual needs. The specified tasks mainly include chapter assignments, afterschool discussions, experimental programs, and design results. The individual needs mainly include the progress of the discipline, the second classroom, research assistants, and scientific literature reading.

\subsection{Combination of theory and practice}

Based on the SPOC teaching platform, teachers set questions on the online learning content before class, and appropriately elaborate or extend the prescribed knowledge points, through face-to-face teaching, micro-video resources, and classroom questions. After-school discussion, course experiment, internship appraisal, experimental program design and other teaching modes, aiming at cultivating students' ability to discover problems, analyze problems and solve problems, and improve the comprehensive ability of pharmacy students. For example, in order to encourage students to take the initiative to learn, enhance the application ability, cultivate innovative consciousness and team spirit, and carry out the flip classroom teaching. Students are grouped, consult relevant materials, write a report outline, report in PPT form, teachers guide and summarize, and evaluate according to the overall performance of the group.

\subsection{Comprehensive evaluation method}

The comprehensive evaluation is carried out by the teachers and students, and the combination of formative and summative evaluation effectively improves the quality and effectiveness of the course teaching. Establish the grade QQ group, the teacher and the squad leader as the administrator, the students real name plus group, the group publishes teaching courseware, practice questions, instruction books, reference documents, etc., as a teacher-student interactive communication platform, based on the usual performance as a scoring reference. The comprehensive experiment "Investigation on the preparation process of peppermint oil inclusion compound" requires that the experimental report be written in the form of a paper, and the results of the experimental report should be evaluated as appropriate. Students are required to write experimental design, the content should be related to pharmacy, such as: dosage form design, preparation, quality control, drug extraction, etc., according to the program quality and reporting results as appropriate. The teacher scores according to the students' attendance, learning situation, answering questions and classroom tests in the classroom teaching. The evaluation is based on the participation degree and task completion on the SPOC teaching platform. At the end of the period, we will integrate the above aspects with the theoretical test scores and conduct a comprehensive evaluation for each student.

\section{Conclusion}

With the rapid development of China's pharmaceutical industry, the content of pharmacy courses should advance with the times, and the teaching mode should be

\section{Published by Francis Academic Press, UK}


improved accordingly to meet the needs of talent training. Actively carry out the SPOC+ hybrid teaching model, and implement "teacher-led, student-centered, and practice-oriented”, which not only enhances students' interest and initiative, but also allows students to actively participate in teaching and teaching. The mixed teaching mode helps students improve their individual potential and comprehensive ability, promotes the cultivation of innovative pharmaceutical application talents, and better serves the current national and economic and social development.

\section{Acknowledgements}

This study was supported by a grant Natural Science Foundation of Shandong Province (ZR2018MH040), Staring Foundation for Doctorate Research of Weifang medical university (2017BSQD50).

\section{References}

[1] Li Wanzhong. Teaching experience of pharmacy course [J]. China Medical Herald. 2008, 5 (2): 113-114.

[2] Bi Yanping, Wang Jianshe, Li Fei, Hao Jifu. Improvement of pharmacy teaching methods in mobile internet environment [J]. Medical Teaching Research in Universities (Electronic Edition), 2017, 7 (3): 40-44.

[3] Li Wei, Hou Guige, Li Hongjuan, Tian Baocheng, Wang Chunhua. Research on Pharmacy Microteaching Model Based on New Media [J]. Basic Medical Education, 2018, 20 (3): 231-234.

[4] Chen Bingmei. Application of problem-based teaching method in the teaching of "pharmaceutical preparations" in higher vocational colleges [J]. Strait Pharmaceutical, 2015, 27 (11): 236-237.

[5] Wang Huarong. Practice and exploration of promoting the reform of university classroom teaching mode with case teaching [J]. Chinese University Education, 2011 (4): 62-64.

[6] Chen Mingwei, Chen Weiwei, Yi Wei, Wang Qin, Chen Hongmei, He Miao. Application of Sandwich teaching method in pharmacy teaching [J]. Huaxia Medical Journal, 2013, 26 (6): 1155-1158.

[7] Xu Jing. Preliminary application of PBL teaching method combined with case teaching method in pharmacy teaching [J]. Health Vocational Education, 2014, 23 (21): 40-41.

[8] Zhou Qingyi, Li Jie, Wu Jielian, Xu Rongrong. Industrial Pharmacy Curriculum Reform Based on Flipping Classroom Teaching Method. Health Vocational Education, 2018, 36 (4): 135-136.

[9] Yi Jun. Construction of pharmacy networked three-dimensional teaching method. Pharmaceutical Education, 2016, 32 (4): 50-52.

[10] Fang Yinglan, Zhang Yongmei, Sun Jing, Liu Gaojun, Song Wei. Research on hybrid teaching mode based on MOOC+SPOC. Computer Knowledge and Technology, 2016, 12 (33): 120-122. 
[11] Yin Hedong. Exploration of the Mixed Teaching Model Based on the PanAsian SPOC Platform in the Post-MOOC Period [J]. Modern Educational Technology, 2015(11): 53-58.

[12] Fang Liang, editor, Pharmacy, People's Medical Publishing House, February 2016, 8th edition. 